\title{
Circular dichroism and circular polarization of photoluminescence of highly ordered poly\{3,4-di[(S)-2- methylbutoxy]thiophene\}
}

\author{
Citation for published version (APA): \\ Langeveld-Voss, B. M. W., Janssen, R. A. J., Christiaans, M. P. T., Meskers, S. C. J., Dekkers, H. P. J. M., \& \\ Meijer, E. W. (1996). Circular dichroism and circular polarization of photoluminescence of highly ordered \\ poly\{3,4-di[(S)-2-methylbutoxy]thiophene\}. Journal of the American Chemical Society, 118(20), 4908-4909. \\ https://doi.org/10.1021/ja9600643
}

DOI:

10.1021/ja9600643

Document status and date:

Published: 01/01/1996

\section{Document Version:}

Publisher's PDF, also known as Version of Record (includes final page, issue and volume numbers)

\section{Please check the document version of this publication:}

- A submitted manuscript is the version of the article upon submission and before peer-review. There can be important differences between the submitted version and the official published version of record. People interested in the research are advised to contact the author for the final version of the publication, or visit the DOI to the publisher's website.

- The final author version and the galley proof are versions of the publication after peer review.

- The final published version features the final layout of the paper including the volume, issue and page numbers.

Link to publication

\footnotetext{
General rights

- You may freely distribute the URL identifying the publication in the public portal. follow below link for the End User Agreement:

www.tue.nl/taverne

\section{Take down policy}

If you believe that this document breaches copyright please contact us at:

openaccess@tue.nl

providing details and we will investigate your claim.
}

Copyright and moral rights for the publications made accessible in the public portal are retained by the authors and/or other copyright owners and it is a condition of accessing publications that users recognise and abide by the legal requirements associated with these rights.

- Users may download and print one copy of any publication from the public portal for the purpose of private study or research.

- You may not further distribute the material or use it for any profit-making activity or commercial gain

If the publication is distributed under the terms of Article $25 \mathrm{fa}$ of the Dutch Copyright Act, indicated by the "Taverne" license above, please 


\section{Circular Dichroism and Circular Polarization of Photoluminescence of Highly Ordered Poly $\{3,4-d i[(S)$-2-methylbutoxy $]$ thiophene $\}$}

\author{
B. M. W. Langeveld-Voss, ${ }^{\dagger}$ R. A. J. Janssen, \\ M. P. T. Christiaans, ${ }^{\dagger}$ S. C. J. Meskers, \\ H. P. J. M. Dekkers ${ }^{\ddagger}$ and E. W. Meijer* ${ }^{*}$
}

\section{Laboratory of Organic Chemistry Eindhoven University of Technology, P.O. Box 513 5600 MB Eindhoven, The Netherlands Leiden Institute of Chemistry, Gorlaeus Laboratories Leiden University, P.O. Box 9502 2300 RA Leiden, The Netherlands}

\section{Received January 8, 1996}

The interesting electrical and optical properties of semiconducting polymers critically depend on the conformation of the $\pi$-conjugated chain in both ground and excited state and on the interchain orientation. ${ }^{1}$ By introducing chirality, the structural characteristics can be assessed with chiroptical techniques, like circular dichroism (CD) and circular polarization of luminescence (CPL). Both techniques are well accepted for probing the conformation of ground and excited state, respectively. ${ }^{2}$ Enantiomerically pure side chains or chiral dopants can afford chiral semiconducting polymers that exhibit optical rotatory dispersion and circular dichroism in the $\pi-\pi^{*}$ band. ${ }^{3}$ Large optical rotations and strong, bisignate, $\mathrm{CD}$ bands have been observed, provided that well-defined and regioregular polymers are used in an associated phase in a poor solvent or in the solid phase. $^{3}$ Here we report on the (chir)optical properties of optically active poly\{3,4-di[(S)-2-methylbutoxy]thiophene $\}$ (PDMBT) and demonstrate that in aggregated phases a splitting of the excited state into two exciton levels occurs. This splitting which cannot be detected in linear absorption or emission is important for understanding photoluminescence and electroluminescence behavior of conjugated polymers. ${ }^{4}$

Optically active PDMBT is prepared from 3,4-di[ $(S)-2-$ methylbutoxy]thiophene. The monomer is prepared from 3,4-

$\dagger$ Eindhoven University.

¥eiden University.

(1) See, e.g.: Proceedings of the International Conference on Science and Technology of Synthetic Metals; ICSM: Seoul, Korea, 24-29 July 1994. Synth. Met. 1995, 69, 71 .

(2) (a) Green, M. M.; Peterson, N. C.; Sato, T.; Teramoto, A.; Cook, R.; Lifson, S. Science 1995, 268, 1860 and references therein. (b) Charney, E. The Molecular Basis of Optical Activity: Optical Rotatory Dispersion and Circular Dichroism; Wiley-Interscience: Chichester, 1979. (c) Dekkers, H. P. J. M. In Circular Dichroism: Principles and Applications; Nakanishi, K., Berova, N., Woody, R. W., Eds.; VCH Publishers: New York, 1994; p 121. (d) Riehl, J. P.; Richardson, F. S. Chem. Rev. 1986, 86, 1.

(3) (a) Elsenbaumer, R. L.; Eckhardt, H.; Iqbal, Z.; Toth, J.; Baughman, R. H. Mol. Cryst. Liq. Cryst. 1985, 118, 111. (b) Lemaire, M.; Delabouglise, D.; Garreau, R.; Guy, A.; Roncali, J. J. Chem. Soc., Chem. Commun. 1988 659. (c) Kotkar, D.; Joshi, V.; Ghosh, P. K. J. Chem. Soc., Chem. Commun. 1988, 917. (d) Anderson, M.; Ekeblad, P. O.; Hjertberg, T.; Wennerström, O.; Inganäs, O. Polym. Commun. 1991, 30, 546. (e) Bouman, M. M.; Havinga, E. E.; Janssen, R. A. J.; Meijer, E. W. Mol. Cryst. Liq. Cryst. 1994, 256, 439. (f) Delabouglise, D.; Garnier, F. Synth. Met. 1990, 39, 117. (g) Salmón, M.; Saloma, M.; Bidan, G.; Genies, E. M. Electrochim. Acta 1989, 34, 117. (h) Harlev, E.; Wudl, F. In Conjugated Polymers and Related Materials. The Interconnection between Chemical and Electronic Structure, Proceedings of the Eighty-First Nobel Symposium; Salaneck, W. R., Lundström, I., Rånby. B., Eds.; Oxford University Press: Oxford, 1993; Vol. 139. (i) Drake, A. F.; Udvarhelyi, P.; Ando, D. J.; Bloor, D.; Obhi, J. S.; Mann, S. Polymer 1989, 30, 1063. (j) Moore, J. S.; Gorman, C. B.; Grubbs, R. H. J. Am. Chem. Soc. 1991, 113, 1704. (k) Havinga, E. E.; Bouman, M. M.; Meijer, E. W.; Pomp, A.; Simenon, M. M. J. Synth. Met. 1994, 66, 93. (1) Bouman, M. M.; Meijer, E. W. Adv. Mater. 1995, 7, 385.

(4) (a) Jenekhe, S. A.; Osaheni, J. A. Science 1994, 265, 765. (b) Samuel, I. D. W.; Rumbles, G.; Collison, C. J. Phys. Rev. B 1995, 52, R11573 (c) Lemmer, U.; Heun, S.; Mahrt, R. F.; Scherf, U.; Hopmeier, M.; Siegner, U.; Göbel, E. O.; Müllen, K.; Bässler, H. Chem. Phys. Lett. 1995, 240, 373. (d) Son, S.; Dodabalapur, A.; Lovinger, A. J.; Galvin, M. E. Science 1995, 261, 376 dimethoxythiophene, ${ }^{5}$ which is treated with 2.2 equiv of $(S)$ (-)-2-methylbutanol under slightly acidic conditions in toluene at $80{ }^{\circ} \mathrm{C}$ to give $3,4-\operatorname{di}[(S)-2$-methylbutoxy]thiophene in $79 \%$ yield after distillation. ${ }^{6}$ Polymerization is accomplished using anhydrous ferric chloride. The polymer is purified and isolated by Soxhlet extractions $\left(M_{\mathrm{w}}=15.4 \mathrm{~kg} / \mathrm{mol}, D=3.49\right) .{ }^{1} \mathrm{H}-$ and ${ }^{13} \mathrm{C}$-NMR spectroscopies reveal the desired 2,5-polymerization without any observable irregularities. This reaction sequence represents a convenient general synthetic route to poly(3,4-dialkoxythiophene)s, since the transetherification is applicable for most of all primary alcohols, making 3,4dimethoxythiophene an interesting synthon.

Linear absorption and circular dichroism spectroscopy of PDMBT in dichloromethane at $20{ }^{\circ} \mathrm{C}$ show that conformationally disordered polymer chains are present with no optical activity in the $\pi-\pi^{*}$ transition at $\lambda_{\max }=438 \mathrm{~nm}$. Cooling to $-30{ }^{\circ} \mathrm{C}$ affords a highly ordered form of PDMBT as evidenced from the significant red-shift of the onset of the absorption and the appearance of a series of well-resolved vibronic transitions at $\lambda_{\max }=508,544$, and $592 \mathrm{~nm}$ (Figure 1). The thermochromic behavior is accompanied by the appearance of a strong, bisignate, and vibronically coupled Cotton effect in the CD spectrum. ${ }^{7}$ The CD spectrum follows the first derivative of the linear absorption spectrum (Figure 1). In $n$-decanol, PDMBT is already highly ordered at room temperature and the degree of circular polarization in absorption, defined as $g_{\text {abs }}=\left(\epsilon_{\mathrm{L}}-\right.$ $\left.\epsilon_{\mathrm{R}}\right) / \epsilon$, is an unsurpassed high for a $\pi-\pi^{*}$ transition. Typically we find $g_{\text {abs }}=2 \times 10^{-2}$ for PDMBT in $n$-decanol at $20^{\circ} \mathrm{C}$, although the actual value critically depends on sample preparation, and values as high as $8 \times 10^{-2}$ have been recorded. This ordered phase of substituted polythiophenes is usually associated with the formation of small aggregates or microcrystallites with interchain interactions. ${ }^{8-10}$

The formation of an ordered phase of PDMBT also results in significant changes in photoluminescence (Figure 2). The emission of the free chains ( $n$-decanol, $110{ }^{\circ} \mathrm{C}$, excitation at $\left.\lambda_{\mathrm{ex}}=450 \mathrm{~nm}\right)$ is strong, with $\lambda_{\max }=558 \mathrm{~nm}$. The excitation spectrum (emission recorded at $\lambda_{\mathrm{em}}=580 \mathrm{~nm}$ ) closely follows the absorption spectrum of free PDMBT chains. The emission of the aggregated phase, recorded at $20^{\circ} \mathrm{C}$, is weaker by 1 order of magnitude, but exhibits a well-resolved vibronically structured emission at $\lambda_{\max }=606,660$, and $\sim 730 \mathrm{~nm}$ when using excitation light with $\lambda_{\mathrm{ex}}>530 \mathrm{~nm}$. When the sample is excited at $\lambda_{\mathrm{ex}}=450 \mathrm{~nm}$, some remaining emission of the disordered chains is observed at shorter wavelengths $\left(\lambda_{\mathrm{em}}=553 \mathrm{~nm}\right)$. The excitation spectrum $\left(\lambda_{\mathrm{em}}=660 \mathrm{~nm}\right)$ of the structured longwavelength emission resembles the absorption spectrum of the aggregates with peaks at $\sim 500,532$, and $580 \mathrm{~nm}^{11}$

The Stokes shift $\left(E_{\mathrm{S}}\right)$ between $0-0$ transitions of absorption and emission in $n$-decanol is less than $90 \mathrm{meV}(25 \mathrm{~nm})$, indicating a small structural reorganization in the excited state. The small Stokes shift is close to the ones observed for other highly ordered polymers such as gel drawn blends of poly[2methoxy-5-(2'-ethylhexoxy)-1,4-phenylene vinylene] in ultrahigh molecular weight polyethylene (UHMW-PE) and ordered

(5) Gronowitz, S. Ark. Kemi 1958, 12, 239

(6) Hoechst, AG. German Patent DE 3804522 A1, 1989.

(7) The CD spectrum is found to be independent of the lateral or angular orientation of the sample with respect to the photomultiplier detector

(8) (a) Rughooputh, S. D. D. V.; Hotta, S.; Heeger, A. J.; Wudl, F. J. Polym. Sci. Polym. Phys. Ed. 1987, 25, 1071. (b) Salaneck, W. R.; Inganäs, O.; Thémans, B.; Nilsson, J. O.; Sjorgren, B.; Österholm, J.-E.; Brédas, J.-L.; Svensson, S. J. Chem. Phys. 1988, 89, 4613. (c) Roux, C.; Bergeron, J.-Y.; Leclerc, M. Makromol. Chem. 1993, 194, 869.

(9) Daoust, G.; Leclerc, M. Macromolecules 1991, 24, 455

(10) In the discussions presented here, we do not distinguish interchain interactions between different polymer chains from those between two parts of a single, but folded, polymer chain.

(11) The absorption spectrum of PDMBT in $n$-decanol at $20{ }^{\circ} \mathrm{C}$ shows vibronically resolved transitions at 497,531 , and $581 \mathrm{~nm}$. 


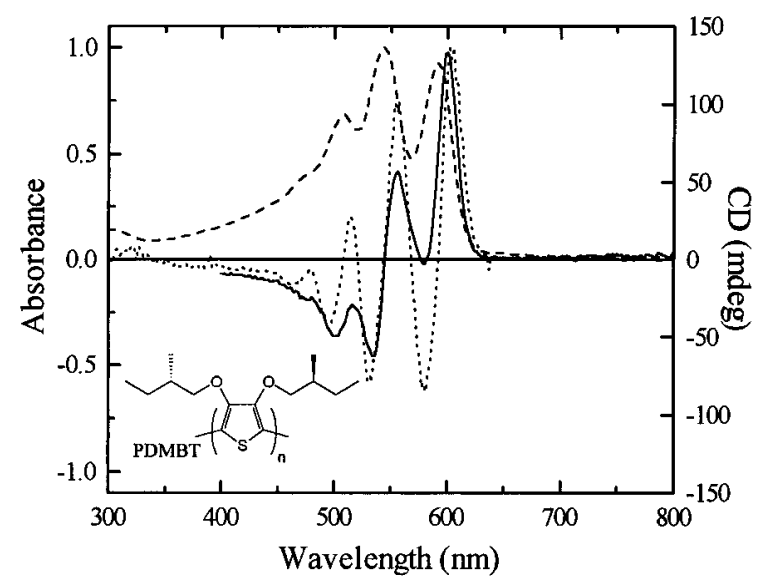

Figure 1. Normalized absorption (dashed line, left axis), first derivative of the absorption (dotted line, left axis), and CD spectrum (solid line, right axis) of PDMBT in dichloromethane at $-30{ }^{\circ} \mathrm{C}$.

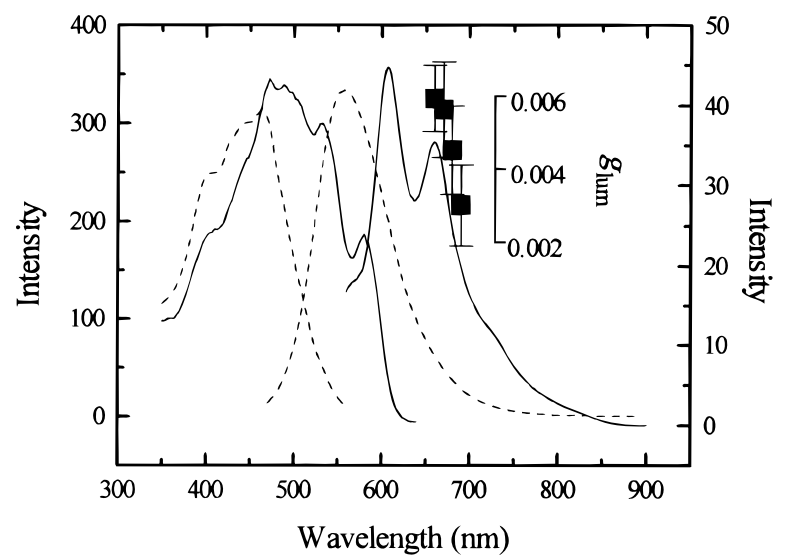

Figure 2. Emission and excitation spectra of PDMBT in $n$-decanol at $20{ }^{\circ} \mathrm{C}$ (solid line, right-hand axis, $\lambda_{\mathrm{ex}}=540 \mathrm{~nm}, \lambda_{\mathrm{em}}=660 \mathrm{~nm}$ ) and at $110{ }^{\circ} \mathrm{C}$ (dashed line, left-hand axis, $\lambda_{\mathrm{ex}}=450 \mathrm{~nm}, \lambda_{\mathrm{em}}=580 \mathrm{~nm}$ ). The inset shows the circularly polarized luminescence spectrum (ם) at $20{ }^{\circ} \mathrm{C}$ of PDMBT in $n$-decanol recorded with excitation at $540 \mathrm{~nm}$.

poly ( $p$-phenylene vinylene) films where $E_{\mathrm{S}}$ ranges from 50 to $70 \mathrm{meV} \cdot{ }^{12,13}$ The linear polarization of the fluorescence in the aggregated phase is high, $p_{\text {lum }} \geq+0.3$, which indicates that the transition dipole moments in the long-wavelength absorption and emission are to a large extent parallel.

In addition to optical activity in absorption we find that the photoluminescence of PDMBT in the associated phase is also circularly polarized. ${ }^{14}$ The degree of circular polarization in emission, defined as $g_{\text {lum }}=2\left(I_{\mathrm{L}}-I_{\mathrm{R}}\right) /\left(I_{\mathrm{L}}+I_{\mathrm{R}}\right)$, shown in Figure 2 has the same sign as $g_{\text {abs }}$ on the high wavelength side. The magnitude of $g_{\text {lum }}$ is on the order of $(+5.0 \pm 1.0) \times 10^{-3}$, a factor of 4 smaller than that in absorption. The exact cause of this difference is presently unclear, but might be related to very small conformational changes (quinoid form) upon photoexcitation or to emission from polymer chains that are defects in the lattice of the aggregate. ${ }^{15}$

(12) (a) Hagler, T. W.; Pakbaz, K.; Voss, K. F.; Heeger, A. J. Phys. Rev. B 1991, 44, 8652. (b) Halliday, D. A.; Burn, P. L.; Bradley, D. D. C.; Friend, R. H.; Gelsen, O. M.; Holmes, A. B.; Kraft, A.; Martens, J. H. F.; Pichler, K. Adv. Mater. 1993, 5, 40.

(13) The confinement parameter $\gamma$ as determined by the ratio of the energies of the $0-0$ transitions in emission and absorption, $\left(\omega_{0} / \Delta_{0}\right)$, is given by $\gamma=\left(\omega_{0} / \Delta_{0}\right) \sin ^{-1}\left(\omega_{0} / \Delta_{0}\right) /\left(1-\left(\omega_{0} / \Delta_{0}\right)^{2}\right)^{1 / 2}$. For PDMBT we find $\gamma=$ 4.3, a value larger than previous estimates of $\gamma \sim 1$ reported for $80 \%$ headto-tail poly(3-alkylthiophene)s. (Xu, B.; Holdcroft, S. Macromolecules 1993, 26, 4457.)

(14) For a description of the instrument, including a detailed analysis of the possible artifacts in the measuring technique, see: Rexwinkel, R. B.; Schakel, P.; Meskers, S. C. J.; Dekkers, H. P. J. M. Appl. Spectrosc. 1993, 47,731 .
The molecular origin of the strong CD effect, and especially the large $g_{\text {abs }}$ value, must be ascribed to a highly ordered packing of the polythiophene chains in a chiral aggregate. The resemblance of the bisignate $C D$ spectrum with the first derivative of the linear absorption spectrum is in full agreement with a splitting of the excited state into two exciton levels via a Davydov interaction. ${ }^{16}$ The full width at half maximum of the first vibronic transition at $-30{ }^{\circ} \mathrm{C}(\sim 70 \mathrm{meV}(20 \mathrm{~nm})$, Figure 1) serves as an upper limit to the energy separation between these exciton levels. The oscillator strengths of the optical transitions to these exciton levels strongly depend on the orientation of the transition dipole moments and for a parallel orientation excitation to (and emission from) the lower level is formally forbidden. ${ }^{16}$ Classical theory on exciton coupling using a point dipole approximation, however, cannot explain high $g_{\text {abs }}$ values as are presently found for PDMBT with long conjugated segments. ${ }^{17,18}$ Therefore, it seems necessary to include either a helical main chain conformation or a delocalization over more than two chain fragments into the theory. The circular polarization in the luminescence of the aggregated form proves that the chirality in conformation or packing is not destroyed by photoexcitation and is in agreement with the small Stokes shift. The relative weak emission observed from aggregates as compared to the optically inactive emission of free chains is a result of a more efficient radiationless decay in the ordered phase. The splitting into exciton levels with different dipole strengths which occurs in aggregates of conjugated polymers is expected to affect the luminescence efficiency and should be taken into account when comparing polymers in different environments (e.g. films vs solutions). Moreover, these results suggest that understanding interchain interactions is important in the design of highly luminescent conjugated polymers. ${ }^{4}$

In summary we have shown that PDMBT can be obtained in a highly ordered phase in solution. The optically active ordered phase of this chiral semiconducting polymer has been studied in detail using CD and CPL spectroscopy and was shown to exhibit a vibronically resolved and circularly polarized absorption and luminescence due to splitting of the excited state into two exciton levels.

Acknowledgment. The authors thank E. E. Havinga, W. ten Hoeve, and M. M. Bouman for valuable discussions and Philips Research for an unrestricted research grant.

Supporting Information Available: $\mathrm{CD}$ and UV/vis spectra of PDMBT at different temperatures in $n$-decanol, ${ }^{1} \mathrm{H}$ and ${ }^{13} \mathrm{C}$ NMR spectra of PDMBT (3 pages). Ordering information is given on any current masthead page.

\section{JA9600643}

(15) For poly\{3-[2-((S)-2-methylbutoxy)ethyl]thiophene\}, a chiral regioregular poly(3-alkylthiophene), ${ }^{3}$ we find a good agreement between circular polarization in absorption and emission: $g_{\text {abs }}=-10 \times 10^{-3}$ and $g_{\text {lum }}=-8.7 \pm 0.6 \times 10^{-3}\left(\lambda_{\mathrm{ex}}=570 \mathrm{~nm}, \lambda_{\mathrm{em}}=660 \mathrm{~nm}\right)$ in $n$-decanol at $20^{\circ} \mathrm{C}$.

(16) For randomly ordered transition dipole moments, on average the lower lying level will have lower oscillator strength: Knox, R. S. J. Phys. Chem. 1994, 98, 7270.

(17) Harada, N.; Nakanishi, K. Circular Dichroic Spectroscopy. Exciton Coupling in Organic Stereochemistry; Oxford University Press: Oxford, 1983.

(18) Classical dipole-dipole theory on exciton coupling of $\pi-\pi^{*}$ states shows that the two split levels have identical rotational strengths of opposite sign (ref 17). Within this model, the magnitudes of the rotational and dipole strengths are determined by the intrinsic dipole strength of the isolated chromophores and their orientation: $R^{ \pm}= \pm(1 / 2) \pi \sigma_{0} \boldsymbol{R}_{\mathrm{ab}}\left(\boldsymbol{\mu}_{\mathrm{a} 0 \mathrm{n}} \times \boldsymbol{\mu}_{\mathrm{b} 0 \mathrm{n}}\right)$; $D^{ \pm}= \pm(1 / 2)\left(\boldsymbol{\mu}_{\mathrm{an}} \pm \boldsymbol{\mu}_{\mathrm{b} 0 \mathrm{n}}\right)^{2}$, where $\sigma_{0}$ and $\boldsymbol{\mu}_{0 \mathrm{n}}$ are the excitation energy and electric transition moment of transition $|0\rangle \rightarrow|n\rangle$, and $\boldsymbol{R}_{\mathrm{ab}}$ is the interchromophoric distance vector. The exciton interaction energy scales with $R_{\mathrm{ab}}{ }^{-3}$. Using this theory, the maximum possible value of $g_{\mathrm{abs}}=4 R / D=\pi \sigma_{0} R_{\mathrm{ab}}$ is independent of the value of the transition dipole moment. It is clear that a value of $g_{\text {abs }}=8 \times 10^{-2}$ measured at $598 \mathrm{~nm}$ is irreconcilable with this exciton model as it would lead to $R_{\mathrm{ab}} \approx 150 \AA$ and, hence, a vanishing small exciton interaction energy, resulting in a zero net $\mathrm{CD}$ effect. 